Published in final edited form as:

Small. 2016 November ; 12(43): 5971-5980. doi:10.1002/smll.201601465.

\title{
Controllable Large-scale Transfection of Primary Mammalian Cardiomyocytes on a Nanochannel Array Platform
}

\author{
Dr. Lingqian Chang ${ }^{\dagger}$, \\ NSEC Center for Affordable Nanoengineering of Polymeric Biomedical Devices, Ohio State \\ University, Columbus, OH 43210, USA \\ Department of Biomedical Engineering, Ohio State University, Columbus, OH 43209, USA \\ Dr. Daniel Gallego-Perez ${ }^{\dagger}$, \\ NSEC Center for Affordable Nanoengineering of Polymeric Biomedical Devices, Ohio State \\ University, Columbus, OH 43210, USA \\ Department of Biomedical Engineering, Ohio State University, Columbus, OH 43209, USA \\ Department of Surgery; Center for Regenerative Medicine and Cell-based Therapies, Ohio State \\ University, Columbus, $\mathrm{OH} 43209$, USA \\ Chi-Ling Chiang, \\ NSEC Center for Affordable Nanoengineering of Polymeric Biomedical Devices, Ohio State \\ University, Columbus, OH 43210, USA \\ Department of Internal Medicine, The Ohio State University, Columbus, OH, 43209, USA \\ Paul Bertani, \\ Electrical and Computer Engineering Department, Ohio State University, Columbus, $\mathrm{OH} 43209$, \\ USA
}

\begin{abstract}
Tairong Kuang,
NSEC Center for Affordable Nanoengineering of Polymeric Biomedical Devices, Ohio State University, Columbus, $\mathrm{OH} 43210$, USA

Dr. Yan Sheng,

NSEC Center for Affordable Nanoengineering of Polymeric Biomedical Devices, Ohio State University, Columbus, OH 43210, USA

Department of Chemical and Biomolecular Engineering, Ohio State University, Columbus, $\mathrm{OH}$, 43210, USA

\section{Dr. Feng Chen,} NSEC Center for Affordable Nanoengineering of Polymeric Biomedical Devices, Ohio State University, Columbus, $\mathrm{OH} 43210$, USA
\end{abstract}

\footnotetext{
Correspondence to: Daniel Gallego-Perez, gal lego-perez. 1 @osu. edu; Wu Lu, lu. $173 @ o s u$. edu; Ly James Lee, lee. 31@osu. edu.

$\dagger$ Equally contributing

Supporting Information

Supporting Information is available from the Wiley Online Library or from the author.
} 
Department of Chemical and Biomolecular Engineering, Ohio State University, Columbus, $\mathrm{OH}$, 43210, USA

\section{Zhou Chen,}

NSEC Center for Affordable Nanoengineering of Polymeric Biomedical Devices, Ohio State University, Columbus, OH 43210, USA

Junfeng Shi, NSEC Center for Affordable Nanoengineering of Polymeric Biomedical Devices, Ohio State University, Columbus, $\mathrm{OH} 43210$, USA

\section{Dr. Xiaomeng Huang,} NSEC Center for Affordable Nanoengineering of Polymeric Biomedical Devices, Ohio State University, Columbus, $\mathrm{OH} 43210$, USA

Department of Internal Medicine, The Ohio State University, Columbus, OH, 43209, USA

\section{Dr. Veysi Malkoc,} NSEC Center for Affordable Nanoengineering of Polymeric Biomedical Devices, Ohio State University, Columbus, OH 43210, USA

Department of Chemical and Biomolecular Engineering, Ohio State University, Columbus, $\mathrm{OH}$, 43210, USA

Prof. Wu Lu, and NSEC Center for Affordable Nanoengineering of Polymeric Biomedical Devices, Ohio State University, Columbus, $\mathrm{OH} 43210$, USA

Electrical and Computer Engineering Department, Ohio State University, Columbus, $\mathrm{OH} 43209$, USA

\section{Prof. Ly James Lee} NSEC Center for Affordable Nanoengineering of Polymeric Biomedical Devices, Ohio State University, Columbus, $\mathrm{OH} 43210$, USA

Department of Biomedical Engineering, Ohio State University, Columbus, $\mathrm{OH} 43209$, USA Chemical and Biomolecular Engineering Department, Ohio State University, Columbus, $\mathrm{OH}$ 43209, USA

Department of Chemical and Biomolecular Engineering, Ohio State University, Columbus, $\mathrm{OH}$, 43210, USA

Daniel Gallego-Perez: gallego-perez.1@osu.edu; Wu Lu: lu.173@osu.edu; Ly James Lee: lee.31@osu.edu

\section{Abstract}

While electroporation has been widely used as a physical method for gene transfection in vitro and in vivo, its application in gene therapy of cardiovascular cells remains challenging. Due to the high concentration of ion-transport proteins in the sarcolemma, conventional electroporation of primary cardiomyocytes tends to cause ion-channel activation and abnormal ion flux, resulting in low transfection efficiency and high mortality. In this work, we report a high-throughput nanoelectroporation technique based on a nanochannel array platform, which enables massively 
parallel delivery of genetic cargo (microRNA, plasmids) into mouse primary cardiomyocytes in a controllable, highly efficient and benign manner. A simple 'dewetting' approach was implemented to precisely position a large number of cells on the nano-electroporation platform. With dosage control, our device precisely titrated the level of miR-29, a potential therapeutic agent for cardiac fibrosis, and determined the minimum concentration of miR-29 causing side effects in mouse primary cardiomyocytes. Moreover, the dose-dependent effect of miR-29 on mitochondrial potential and homeostasis was monitored. Altogether, our nanochannel array platform provides efficient trapping and transfection of primary mouse cardiomyocyte, which could improve the quality control for future microRNA therapy in heart diseases.

\title{
TOC image
}

\begin{abstract}
An nanochannel array platform trap and precisely transfect primary adult mammalian cardiomyocytes with high efficiency /cell viability. A simple 'dewetting' approach precisely positions single cell on chip. Nanochannel-based electroporation can determine the dose of delivery, offering quality control of microRNA-based gene therapy in cardiovascular cells as demonstrated by delivering miR-29 into primary cadiomyocytes for determining dose effect for apoptosis.
\end{abstract}

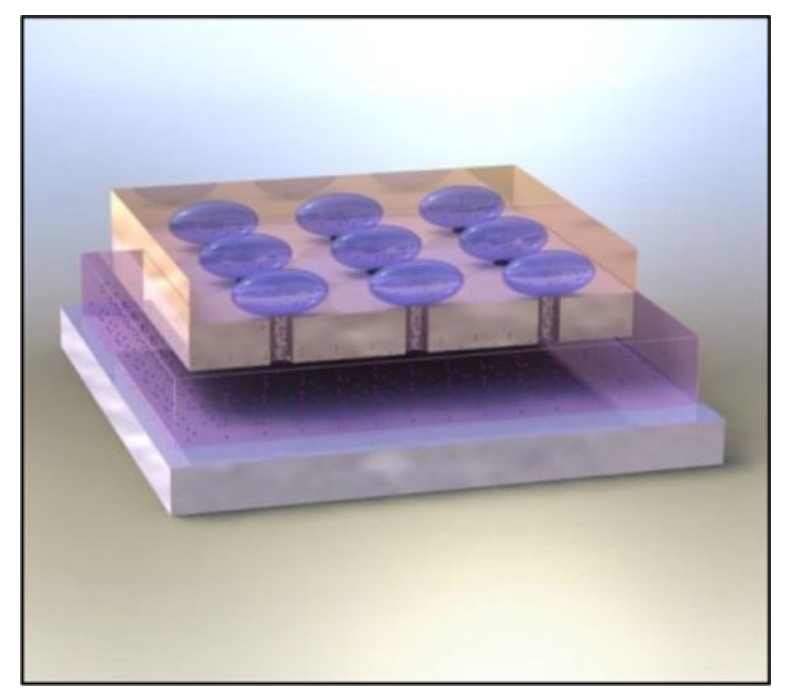

\section{Keywords}

Nanochannel array; nano-electroporation; primary adult cardiomyocytes; miR-29; mitochondrial potential

\section{Introduction}

Owing to its user-friendliness and high-throughput, electroporation is one of the most commonly used physical techniques for gene / drug delivery, with great potential for medical and clinical applications ${ }^{[1]}$. Compared to chemical methods, electroporation can bypass endocytosis, thus overcoming 'multi-drug resistance' responses from cells ${ }^{[2]}$. There is no need for cargo pre-packaging ${ }^{[3,4]}$. Commercial bulk electroporation (BEP) systems have 
been widely used both in vitro and in vivo ${ }^{[5,6]}$. However, due to its bulk-environment where extremely high voltage is randomly applied on individual cells, BEP usually results in significant cellular damage ${ }^{[5,7]}$. Recent advances in microfluidic-based electroporation (MEP) have enabled more benign transfection at lower voltage ${ }^{[8]}$. Nevertheless, both BEP and MEP are highly dependent on additional factors downstream of poration (i.e., endocytosis, diffusion), which lead to low and variable transfection yields at the single cell level ${ }^{[3,9]}$.

BEP/MEP based transfection of electrogenic (excitable) cells also remains challenging ${ }^{[10-13]}$. The primary function of cardiomyocytes is regulation of the contractionrelaxation cycles of hearts ${ }^{[14]}$. Their self-regulated contractibility, achieved by ion channels and exchangers that control the transportation of $\mathrm{Ca}^{2+}$, is highly sensitive to external electrical stimulation. In BEP and MEP, large portions of the sarcolemma are exposed to the porating electric field, which results in ion-channel over-activation and abnormal ion flux, that trigger functional disorders and apoptosis ${ }^{[10,13]}$. Although pioneering work has been conducted on designs of electroporation-assisted intracellular probes for electrical recording of cardiomyocytes cell lines (e.g. HL-1) ${ }^{[15]}$, safe and efficient electroporation systems for high-throughput transfection of primary adult cardiomyocytes in vitro are currently lacking.

We recently demonstrated nanochannel electroporation (NEP) technique for living cell transfection in a highly controllable manner ${ }^{[9,16]}$. In NEP, a single cell is positioned in tight contact with a single nanochannel $(100-400 \mathrm{~nm})$ while cargo on the other side of the nanochannel. As the equivalent resitance of nanochannel (> $100 \mathrm{M} \Omega)$ is significantly higher than the that of cell membrane $(<10 \mathrm{M} \Omega)$, most of the applied voltage is distributed over the nanochannel. The NEP involves benign and highly-confined membrane poration (nearby the nanochannel), as well as high-voltage (> $100 \mathrm{~V})$ induced electrophoresis-effect, which 'shoot' cargo into cytoplasm, resulting in high transfecion efficiencies and dose-control capabilities. Our previous NEP systems, however; are compromised on the transfection yields due to either nanochannel design (e.g. 2D NEP) ${ }^{[9,17]}$ or cell trapping methods ${ }^{[18]}$. In this work, we report manipulation and transfection of primary adult mammalian cardiomyocytes with high efficiency and cell viability on a nanochannel array platform. Our device enables high throughput parallel delivery of functional cargo (e.g. transcription factors, oligonucleotides, molecular beacons) into cells via electroporation through nanochannels. Dose of cargo can be precisely controlled by external electric field (e.g. voltage, pulse length, and pulse number). A novel 'dewetting' approach was implemented to precisely position the cells-to-be-transfected in direct contact with the porating nanochannels in a high throughput manner. Such a method is simple and fast, without a requirement for sophisticated systems and special buffers. Our device demonstrated transfection of adult mouse cardiomyocytes with high efficiency and safety. We applied the device to investigate the dose effect of microRNAs for cardiomyocyte therapy. Currently, loss of miR-29 is known to be associated with cardiac fibrosis, providing a clinical potential therapeutic agent for cardiac fibrosis by targeting TGF- $\beta /$ Smad 3 signaling ${ }^{[19]}$. However, the two faces of miR-29 in cardiovascular disease step it back. ${ }^{[20]}$ The deletion of mitochondrial Mcl-1, a main target of miR-29 in cardiomyocyte, leads to heart disorganization, inflammation, and even lethal heart failure ${ }^{[21,22]}$. Therefore, preserving $\mathbf{M c l}-1$ and maintaining mitochondrial homeostasis is essential to the consideration of the miR-29 
family in clinical application ${ }^{[23]}$. Endocytosis / diffusion based delivery, as well as poor transfection efficiency of primary cardiomyocyte (typically $<5 \%$ ) by liposomes and $\mathrm{BEPs}^{[11,24]}$, makes them impractical for optimizing the dosage of microRNA therapy in most applications in cardiomyocytes. In this work, miR-29 was delivered into an array of primary adult mouse cardiomyocytes on-chip, and the dose-dependent effects of miR-29 on mitochondrial potential and homeostasis of a cardiomyocyte was analyzed. The statistics, based on a large number of cells, proved quality control of clinical microRNA therapy on heart disease.

\section{Results and Discussion}

\subsection{Precise large-scale cell positioning on nanochannel array}

Successful nanochannel-based electroporation requires direct cellular contact with the nanochannels. We developed a simple 'dewetting' approach for this purpose, as illustrated in Figure 1a. In this procedure, a micro-cap array (SU8 photoresist) was patterned over nanochannel array on a silicon chip (fabrication details in Figure S1). Each micro-cap consists of a 'U-shape' feature that contains a front-side cup for cell entry. To enhance cell flow, the chip surface was pre-treated to be hydrophilic using piranha solution and oxygen plasma (step (i), Figure 1a). For precise cell positioning, the chip, with the 'U-shape' of micro-cap facing up, was vertically dipped-in $(\sim 5 \mathrm{~min})$ and -out of a cell suspension $\left(\sim 10^{6}\right.$ cells / $\mathrm{ml}$ ) in phosphate-buffered saline (PBS). Gravity and hydrodynamic forces modulated cell trapping within the micro-caps, directly over top of the nanochannel outlets (step (ii)). Tailoring the geometries of the microcap array to be slightly larger than the cell size can achieve single-cell capture in a single cup, resulting in a clear cellular array on the chip surface (step (iii)). Figure 1b shows a cross-section of the chip. Trapped by the micro-cap, the cell contacts with the nanochannel so that it can be effectively electroporated while target biomolecules are delivered into cytosol, as illustrated in Figure 1c. Precise alignment of the micro-cap to nanochannel region plays a critical role in transfection efficiency. We therefore aligned each micro-cap to a nanochannel in photolithography (Figure 1d). We designed a family of micro-cap arrays with different dimensions and spacing to optimize the trapping efficiency (Figure 1d and Figure S2). Our results indicate that in the 'dewetting' procedure, micro-cap array with smaller geometries (width: $5 \mu \mathrm{m}$, spacing: $25 \mu \mathrm{m}$ ) result in low capture efficiency ( $10 \%$ micro-caps with single cell trapped) but relatively high capture specificity ( $~ 80 \%$ loaded cells aligned on the nanochannel, enabling electroporation), as shown in Figure S2c-d. In contrast, increasing the geometries (width: $10 \mu \mathrm{m}$, spacing: $50 \mu \mathrm{m}$, Figure $\mathrm{S} 2 \mathrm{a}-\mathrm{b})$ is prone to clogging, which leads to low capture specificity ( $30 \%)$. Finally, we chose the 'interlaced' micro-cap array (Figure 1d, cap width: $\sim 10 \mu \mathrm{m}$, column and row spacing: $100 \mu \mathrm{m}$ ) for subsequent experiments, which achieved remarkably high capture efficiencies and specificities ( 70 - 90\% and 90\%) (Figure 1e-f).

\subsection{On-chip massively parallel cargo delivery}

A high-throughput nanochannel-based transfection platform that delivers cargo into the cells patterned on the chip is illustrated in Figure 2a-b. Following 'dewetting', the chip was mounted on a polydimethylsiloxane (PDMS) reservoir that contained the cargo (e.g., labeled DNA, plasmids, microRNAs). The 3D image by confocal microscopy (Figure 2c) shows that 
loaded cells (stained with Calcein AM, green fluorescence) are tightly in contact with individual nanochannels (white light). The nanochannel-based electroporation and its mechanism of delivery are illustrated in Figure 2d. A pulsed electric field was implemented to porate the cell membrane in contact with the nanochannel. In the meantime, the surfacecharged target cargos are electrophoretically driven through each nanochannel and are delivered into the cytosol in a fast (i.e., milliseconds) and efficient manner. Physical simulation results show that due to the high equivalent resistance of the nanochannel, the biased voltage applied on single cell is relatively uniform $(1.84 \mathrm{~V}-2.00 \mathrm{~V})$ over the chip surface $\left(1 \mathrm{~cm}^{2}\right)$ within a proper liquid film (e.g. $5 \mathrm{~mm}-1 \mathrm{~cm}$ ), in the system shown in Figure 2d. Increasing the liquid film will reduce the biased voltage across the cell (Supplementary Note 1). We first explored the capability of our device for massively parallel cell transfection and the 'dewetting' approach for improvement in transfection efficiency. Figure 2e-f show a single-cell array (mouse embryonic fibroblasts, MEFs) is delivered with FAM-ODNs (FAM-labeled oligonucleotides) on our platform. The combination of 'electrophoretic-injection' and dewetting-based cell patterning results in transfection efficiencies around $90-100 \%$ (Figure $2 \mathrm{~g}$ ) compared to only $\sim 10 \%$ for random cell loading. Furthermore, note that the cells 'off' the micro-cap (labelled with blue circle in Figure 2e and f) could not be transfected, thus confirming that only cells positioned to the nanochannels can be effectively porated. We next tested the performance of the device for trans-genetic manipulation of living cells. MEFs were transfected with GFP plasmids (pMax, $3.5 \mathrm{kbp}$ ) showed obvious green fluorescence expression in $6 \mathrm{hr}$ (Figure 2h-i, mass cell GFP expression in Figure S3). In control group, randomly-loaded cells results in weak GFP expression (Figure $2 \mathrm{~g}$ and $\mathrm{k}$ ). Figure $2 \mathrm{l}$ shows that the average GFP intensities in 'dewetting' group are $\sim 6$-fold higher than the control group, while showing promising uniformity (s.d. $3.5 \%$ ). With the 'dewetting' approach, the cells can be trapped and transfected within several minutes at a high-throughput, which is time-efficient in observing previously reported microfluidics (up to hours for high throughput) ${ }^{[25]}$, optical tweezers (minutes for single-cell $)^{[9,26]}$, dielectrophoresis $(\sim 30 \text { minutes })^{[27]}$, magnetic tweezers $(\sim 10$ minutes $)^{[28,29]}$. Moreover, 'dewetting' protocol requires no sophisticated systems for force generation, which is simpler for clinical use.

\subsection{Efficient and controllable gene delivery into adult mouse cardiomyocytes}

The major function of adult cardiomyocytes is to orchestrate the contraction and relaxation of the heart. The contractility of a single cardiomyocyte is controlled by transmembrane ion channels (mainly, $\mathrm{Ca}^{2+}$ ), whose functionality can be easily compromised by external electrical stimuli ${ }^{[14]}$. As such, BEP-based gene delivery to cardiomyocytes typically results in low efficiencies $(\sim 10 \%)^{[12,30]}$, and significant cell death due to abnormal ion flux, contraction interference and membrane damage ${ }^{[10,13]}$. We tested the capabilities of our nanochannel-based transfection approach to deliver genes into primary cardiomyocytes in vitro in a controllable and benign manner. A high percentage of cardiomyocytes keep alive while expressing obvious fluorescence after transfection with GFP plasmids (Figure 3a, single cell was shown in Figure S4). Compared to control group (in vitro culture without treatment, see Figure S6), the GFP intensity increased by $\sim 10-12$-fold at $6 \mathrm{hr}$ posttransfection, as shown in Figure 3b. Clear GFP expression was still present after $24 \mathrm{hr}$ (Figure S5). BEP experiments, which were also conducted for comparison purposes, 
resulted in low transfection efficiency and significant cell damage (Figure S6). While our device yielded transfection efficiencies and cell viabilities $\sim 86 \%$, BEP-based transfection led to efficiencies and viabilities of $\sim 5 \%$ and $13 \%$, respectively (Figure 3c-d). MEP experiments (with channel size of $5 \mu \mathrm{m}$ ), on the other hand, did not result in clear GFP transfection and expression (Figure S6), presumably due to the need for the use of low voltages $(\sim 4 \mathrm{~V})^{[29]}$. Figure $3 \mathrm{e}$ demonstrates that our platform precisely control the dosage of FAM-ODN delivered into cardiomyocytes by applied voltages ranging from $0 \mathrm{~V}$ to $200 \mathrm{~V}$. Besides, the delivered dose could be controlled by the pulse durations (e.g., $5 \mathrm{~ms}, 10 \mathrm{~ms}, 20$ ms) as well (Figure 3f). Furthermore, we demonstrated our device achieved significantly higher transfection uniformity at single-cell level than BEP, as measured by flow cytometry at high-throughput (Figure S9). Altogether, our nanochannel array device demonstrated the unique capability for controllable mass cardiomyocyte transfection (>10,000 cells per chip).

\subsection{Simulation of cardiomyocytes electroporation via nanochannel}

Observing the striking contrast between BEP and our device for transfection of primary cardiomyocytes, we next discuss the particular reason. Physical models were generated to analyze the electric fields for both nanochannel- and bulk- based electroporation at the single-cell level (Figure 4a-e). The electric field distribution of our device, in which two single cardiomyocytes (represented as 'rectangle-shape') are localized on two nanochannels, is illustrated in Figure 4a. The simulation reveals that due to the high-resistivity of the nanochannel, among the voltage $(100 \mathrm{~V})$ applied in the whole system, approximately $96 \%$ of the voltage drop occurs across the nanochannel, which provides high electrophoretic motility to the gene cargo during transfection. Only about $4 \%$ of the applied bias ( 4V, Figure $4 \mathrm{~b})$ is directed to the cell membrane (as determined by the nanochannel diameter). Such drop is just above the transmembrane potential threshold (usually $\sim 0.5-1 \mathrm{~V}$ ) needed to porate the membrane and allow cytosolic injection of the cargo. Furthermore, only a small portion of the cell membrane is exposed to the electric pulse (Figure 4c), as determined by the nanochannel size. In comparison, microchannel- or bulk-based electroporation affect significantly larger portions of the cell membrane (several $\mu \mathrm{m}$ to the whole surface), which tends to negatively compromise cell viability. With a non-spherical shape, the cardiomyocyte could be electroporated over the whole membrane instead of the poles oriented to the electric field, thus causing additional cellular damage in BEP and MEP (Figure 4d) ${ }^{[31]}$. Finally, single-cell level analysis of the electric field distribution in BEP reveals significant cell-to-cell variations (Figure 4e), thus resulting in more stochastic transfection profiles compared to the more deterministic nature of nanochannel-based gene delivery ${ }^{28}$. In both $\mathrm{BEP}$ and MEP, low electric field $(<50 \mathrm{~V} / \mathrm{cm})$ cannot sufficiently electroporate cells. ${ }^{[10,13]}$.

\subsection{Dose-controlled delivery studies of miR-29 with primary mouse cardiomyocytes}

Loss of miR-29 expression in cardiomyocytes leads to cardiac fibrosis ${ }^{[19]}$. Although strategies aimed at replenishing miR-29 levels could offer a viable treatment for the condition, the potential side effects of this approach need to be carefully investigated. Here we used our unique nanochannel-based delivery platform to thoroughly evaluate the effects of precisely-dosed miR-29 delivery on cardiomyocyte behavior. Normal cardiomyocytes express high miR-29, but the overexpression of miR-29 results in mitochondrial dysfunction (i.e., loss of mitochondrial potential) and cell apoptosis ${ }^{[2]}$. We delivered the gradient 
amount of miR-29b ${ }^{[32]}$ by modulating the number of applied pulses (1-10 pulses).

Tansfected cardiomyocytes were stained with JC-1 and analyzed by flow cytometry. JC-1 dye performs a potential-dependent accumulation in mitochondria with a fluorescence shift from green $(\sim 529 \mathrm{~nm})$ to red $(\sim 590 \mathrm{~nm})$. The ratio of red (dimer)/green (monomer) reflected to the mitochondrial potential $(\Delta \Psi)$ of transfected cells (Figure 5a). The increasing of pulse from $0,1,5$, to 10 significantly cause the mitochondrial depolarization and decrease in the number of high $\Delta \Psi$ cells (Figure $5 \mathrm{~b}$ ). By using the real-time PCR, we measured the intracellular miR-29 and its target $\mathrm{Mcl}-1$ amount post nano-electropration. $\mathrm{Mcl}-1$ is also highly expressed in normal myocardium, playing an essential role in myocardial homeostasis and autophagy ${ }^{[22]}$. We observed the increased miR-29b dose could significantly suppress the $M c l-1$ expression in living cells (Figure 5c). Such a dose-dependent manner provides a hint to precisely study the threshold-dose causing the disorder of the mitochondrial homeostasis in miR-29-based gene therapy.

\section{Conclusion}

Primary cardiomyocytes with fully differentiated status are generally known to be difficult to transfect with non-viral approaches. Liposomal or BEP transfection of primary cardiomyocytes typically performs extremely poorly, with efficiencies of less than $5 \%$. In addition, BEP causes significant cell damage. Novel technologies capable of delivering genetic cargo to electrogenic cells in a controlled, efficient and benign manner are clearly needed in order to facilitate the development of gene therapies for cardiac tissue, and/or enable a host of critical studies of cardiac cell biology and physiology. In this work, we reported a nanochannel array platform for large-scale single-cell trapping and on-chip transfection of primary cardiomyocytes at a high-throughput. A fluidic-based 'dewetting' method was developed to trap and precisely align an array of individual cells on the nanochannel chip where the electroporation condensed. Our device assisted with dewetting demonstrated unprecedentedly high transfection efficiencies and dosage control capabilities with single-cell resolution, which is not achievable with any existing technology. We achieved a linear dosage control of miR-29 delivery in primary mouse cardiomyocyte, providing a titration of miR-29 effects on primary cardiomyocytes for further clinical application. In conclusion, our platform provides an efficient trapping and electroporation method with precise dosage control on primary mouse cardiomyocyte, which will improve the clinical microRNA therapy on heart disease.

\section{Experimental Section}

\subsection{Nanochannel array chip fabrication}

The nanochannel array chip was made using a silicon wafer via clean room techniques (Figure S1) ${ }^{[18,33]}$. A standard double-side polished (DSP) wafer (4 inch, $500 \mu \mathrm{m}$ in thickness) was first thinned to $250 \mu \mathrm{m}$ using wet etching $\left(45 \% \mathrm{KOH}, 80^{\circ} \mathrm{C}\right)$. A micro-circle array (50 $\mu \mathrm{m}$ in diameter) was then patterned on one side of the chip using SPR220 photoresist (Dow Chemicals, US). Deep reactive ion-etch (DRIE) was applied to etch the photoresist-masked side so that a microchannel array (diameter: $50 \mu \mathrm{m}$; depth: $240 \mu \mathrm{m}$ ) was formed. An array of nanochannel was then patterned using AZ-5214 photoresist (Clariant 
Corporation, US), and DRI-etched until the nanochannels connected with the microchannels. In our experiments, each chip, with $1 \mathrm{~cm}^{2}$ nanochannel array area, was diced from the whole wafer after etching. The silicon based nanochannel chip is reproducible as the nanofabrication techniques, i.e. projection photolithography and DRIE, are robust with optimized protocols.

\subsection{Micro-cap array pattern}

The micro-cap array was made using SU-8 2015 (MicroChem), which was spun on the fabricated the nanochannel array chip. The heights of microcaps were fixed at $\sim 5-10 \mu \mathrm{m}$. For alignment between micro-cap array and nanochannel array, a male 'cross' marker was patterned and etched on the chip during the nanochannel etching process. A female 'cross' marker on the photomask with the micro-cap array pattern was used to track the relative location between the micro-cap array feature and the nanochannel array on the chip. The alignment process and photolithography were performed on an automated UV-aligner (EVG 620). Every microcap feature in our design has an opening at the back-side, which is used to facilitate the entry of the cells when the liquids flow 'through' the middle of the micro-cap.

\section{3. 'Dewetting' for on-chip cell trapping and release}

Prior to cell trapping, the chip patterned with micro-cap arrays was treated to be hydrophilic with Piranha solution ( $96 \%$ sulfuric acid, $120^{\circ} \mathrm{C}$ ) and oxygen plasma (PTS oxygen plasma system), and was exposed under UV-light for sterilization. Cells were transferred from cell culture medium to PBS solution, and then were transferred into a column glass tube (diameter: $1.5 \mathrm{~cm}$; height: $5 \mathrm{~cm}$ ) in a density of $\sim 1$ million / $\mathrm{ml}$. The chip, with the 'U-shape' cup facing up, was then immersed into cell buffers and was held for $\sim 5$ mins (the chip was in an angle of $60^{\circ}-90^{\circ}$ to horizon). In the procedure of 'dewetting', the chip was gently and slowly lifted up $(\sim 2 \mathrm{~cm} / \mathrm{min})$ using tweezers. One advantage of the procedure is that nearly all the cells that are not trapped could flow back to the cell buffer in 'dewetting' process (allowing conservation of materials), repeated 'dipping-trapping' was usually made in order to achieve a high capture efficiency. We note that term 'dewetting' in our experiments did not indicate that the chip surface is dry, but specifically describes the liquid movement across the chip. In fact, a thin liquid film forms on the chip surface after 'dewetting' and lasts for several mins before vaporized. Such a time-duration gives enough time to perform on-chip electroporation.

After electroporation, the chip was transferred into $1 \mathrm{ml}$ cell culture medium in a 6-well plate. A $200 \mu$ l pipette was used to gently wash the chip surface from the opposite direction to the cell trapping. As the opening of the microcap (as shown in the inset of Figure 1b) was designed for buffer flow through and cell release, the hydrodynamic force by pipette easily move the cells out of the 'U-shape' microcaps and float back into the medium in an incubator $\left(37^{\circ} \mathrm{C}, 5 \% \mathrm{CO}_{2}\right)$ for further applications.

\subsection{High-throughput nano-electroporation platform}

A bottom electrode was made from a glass slide $(25 \mathrm{~mm}$ by $75 \mathrm{~mm}$ ) coated with a gold layer (50 nm, Denton 520 evaporator). A PDMS (Polydimethylsiloxane) spacer (width and length: $1 \mathrm{~cm}$, thickness: $1 \mathrm{~mm}$ ) was mounted on the gold-coated glass, forming a bottom chamber 
filled with cargo solutions. After cells were trapped, the chip was gently placed on the bottom chamber. A top electrode (commercial electrode, Neon Transfection System) was moved to touch the buffer film on the chip surface in the connection as illustrated in Fig. 2d. A series of voltage pulses (voltage: $0-200 \mathrm{~V}$, duration: $0-30 \mathrm{~ms}$ ) were generated from a power supply (lab-made) for cellular electroporation. All components were sterilized with a $70 \%$ alcohol solution and UV-light.

For comparison, BEP was performed using a commercial system (Neon Transfection) and the operation was consistent with the instructions online. The MEP system used in cardiomyocytes transfection was based on a silicon 3D microchannel array chip. Each microchannel was $5 \mu \mathrm{m}$ in diameter. Based on our previous research, $4 \mathrm{~V}$ is a safe voltage for cell electroporation ${ }^{[29]}$. In microchannel based electroporation, however; a sufficiently high voltage would cause irreversible cell membrane damage due to several reasons, including irreversible pore formation, $\mathrm{pH}$ change, thermal issues, etc ${ }^{[10]}$.

\subsection{Cells collection, culture and transfection}

Mouse embryonic fibroblasts (MEFs) were isolated from E12.5 embryos, and were cultured in Dulbecco's Modified Eagle's Medium (DMEM, Catalog no. 30-2002) with addition of $10 \%(\mathrm{v} / \mathrm{v})$ fetus bovine serum (FBS, heat inactivated, Catalog no. 26010) and non-essentialamino acids. Mouse cardiomyocytes were isolated from adult mice, and were cultured in Dulbecco's Modified Eagle's Medium (DMEM, Catalog no. 30-2002) with addition of 10\% $(\mathrm{v} / \mathrm{v})$ fetus bovine serum (FBS, heat inactivated, Catalog no. 26010) and non-essential-amino acids. FAM labeled oligonucleotides (FAM-ODN, alpha DNA Co., Catalog no. 427520, excitation /emitting wavelength, 492/517 nm) were used to test the performance of nanoelectroporation in gene delivery, while PmaxGFP (3.5 kbp, Catalog no. VSC-1001, Amaxa Nucleofector Technology) was used to test the transfection performance. Hoechst (SigmaAldrich, catalog No. 654434, excitation/emitting wavelength, 350/461 nm) was used to stain nuclei.

\subsection{Image acquisition and data analysis}

As the silicon chip is non-transparent, imaging the on-chip cell trapping and FAM-ODN delivery was performed on an upright microscope (Leica DM2500). An inverted microscope (Nikon Eclipse Ti) was used to record fluorescent expressions of cells cultured off-chip. 3D cell-nanochannel image was reconstructed from slice-images by a fluorescence confocal microscope (Olympus FV1000).

COMSOL Multiphysics was used to analyze the electric field in both BEP and nanochannel electroporation systems ${ }^{[34]}$. The governing equation for the system (static electric field) used is: $\nabla \cdot(\sigma \nabla V)=0$. where $\sigma$ is the conductivity. The average length of the nanochannel is 13 $\mu \mathrm{m}$, the diameter of nanochannel is $400 \mathrm{~nm}$. Conductivities of extracellular fluid (PBS) and the cytosol are $0.8 \mathrm{~S} / \mathrm{m}$ and $0.2 \mathrm{~S} / \mathrm{m}$, respectively. The cellular membrane is estimated to be $5 \mathrm{~nm}$ thick with a conductivity of $5 \times 10^{-7} \mathrm{~S} / \mathrm{m}$. In BEP system, the orientation of the cells and the number of cells ( 8 cells) are radomly generated. 
Two-sided student T-test was used to determine the significance for data with Gaussian distribution and equal variances. Groups with p-values $<0.05$ were considered significant difference.

\subsection{RNA extraction and realtime PCR}

Total RNA extraction was carried out by using Trizol (Invitrogen) and cDNA was made using random primers (Invitrogen, Life Technologies). Real-time PCR was performed by using TaqMan (Life Technologies) gene expression assay probe primer sets for miR-29b and Mcl-1 by ViiA 7 Real-Time PCR System (Applied Biosystems, Grand Island, NY, USA). The expression of target genes relative to internal control gene was calculated using the threshold cycle number $(\mathrm{Ct})$. The relative target gene expression for each condition was normalized to control and fold change determined using the comparative method ( $2 \Delta \Delta \mathrm{Ct})$.

\subsection{Mitochondrial potential measurement}

After the transfection of miR-29b, the cardiomyocytes were stained with JC-1 to determine the mitochondrial membrane potential. JC-1 is a membrane-permeable lipophilic dye that acts as J-aggregates in the mitochondrial matrix (red fluorescence; $590 \mathrm{~nm}$ ) and as monomers in the cytoplasm (green fluorescence, $529 \mathrm{~nm}$ ). As mitochondrial depolarization happens, the red J-aggregates change to green monomers due to the loss of $\Delta \Psi$. Thus, mitochondrial $\Delta \Psi$ can be measured as an index of red (dimer)/green (monomer) fluorescence ratio. The stained cardiomyocytes were rinsed twice with media and analyzed with a flow cytometry (Beckman-Coulter, Brea, CA, USA).

\subsection{Statistical Analysis}

Two-sided student T-test was used to determine the significance for data. The groups with $\mathrm{p}$ values $<0.05$ were considered statistically significant.

\section{Supplementary Material}

Refer to Web version on PubMed Central for supplementary material.

\section{Acknowledgments}

The authors are grateful to the National Science Foundation (EEC-0914790) and NIH (1R21EB017539-01A1) for supporting this study. The authors thank Dr. Zhaogang Yang for conceiving the idea on cardiomyocytes transfection.

\section{References}

1. Kaji K, Norrby K, Paca A, Mileikovsky M, Mohseni P, Woltjen K. Nature. 2009; 458:771. [PubMed: 19252477] Szczurkowska J, Cwetsch AW, Dal Maschio M, Ghezzi D, Ratto GM, Cancedda L. Nat Protoc. 2016; 11:399. [PubMed: 26844428] dal Maschio M, Ghezzi D, Bony G, Alabastri A, Deidda G, Brondi M, Sato SS, Zaccaria RP, Di Fabrizio E, Ratto GM, Cancedda L. Nat Commun. 2012; 3

2. Meschini S, Condello M, Lista P, Vincenzi B, Baldi A, Citro G, Arancia G, Spugnini EP. Eur J Cancer. 2012; 48:2236. [PubMed: 22240284] Sheng Y, Chang LQ, Kuang TR, Hu JM. Rsc Adv. 2016; 6:23279. 
3. Chang L, Hu J, Chen F, Chen Z, Shi J, Yang Z, Li Y, Lee LJ. Nanoscale. 2016; 8:3181. [PubMed: 26745513]

4. Yang ZG, Chang LQ, Chiang CL, Lee LJ. Curr Pharm Design. 2015; 21:6081.

5. Wang SN, Lee LJ. Biomicrofluidics. 2013; 7

6. Liu F, Heston S, Shollenberger LM, Sun B, Mickle M, Lovell M, Huang L. J Gene Med. 2006; 8:1192.

7. Prausnitz MR, Bose VG, Langer R, Weaver JC. P Natl Acad Sci USA. 1993; 90:10504.

8. Kang W, Giraldo-Vela JP, Nathamgari SSP, McGuire T, McNaughton RL, Kessler JA, Espinosa HD. Lab Chip. 2014; 14:4486. [PubMed: 25205561] Khine M, Lau A, Ionescu-Zanetti C, Seo J, Lee LP. Lab Chip. 2005; 5:38. [PubMed: 15616738] Matsuda T, Cepko CL. Proc Natl Acad Sci U S A. 2004; 101:16. [PubMed: 14603031] Pinyon JL, Tadros SF, Froud KE, Wong ACY, Tompson IT, Crawford EN, Ko M, Morris R, Klugmann M, Housley GD. Sci Transl Med. 2014; 6

9. Boukany PE, Morss A, Liao WC, Henslee B, Jung HC, Zhang XL, Yu B, Wang XM, Wu Y, Li L, Gao KL, Hu X, Zhao X, Hemminger O, Lu W, Lafyatis GP, Lee LJ. Nat Nanotechnol. 2011; 6:747. [PubMed: 22002097]

10. Klauke N, Smith G, Cooper JM. Anal Chem. 2010; 82:585. [PubMed: 20020746]

11. Louch WE, Sheehan KA, Wolska BM. J Mol Cell Cardiol. 2011; 51:288. [PubMed: 21723873]

12. Frias MA, Rebsamen MC, Gerber-Wicht C, Lang U. Cardiovasc Res. 2007; 73:57. [PubMed: 17067562]

13. Bokenes J, Sjaastad I, Sejersted OM. J Appl Physiol. 2005; 98:1712. [PubMed: 15640393]

14. Woodcock EA, Matkovich SJ. Int J Biochem Cell B. 2005; 37:1746.

15. Xie C, Lin ZL, Hanson L, Cui Y, Cui BX. Nat Nanotechnol. 2012; 7:185. [PubMed: 22327876] Santoro F, Dasgupta S, Schnitker J, Auth T, Neumann E, Panaitov G, Gompper G, Offenhausser A. ACS Nano. 2014; 8:6713. [PubMed: 24963873] Spira ME, Hai A. Nat Nanotechnol. 2013; 8:83. [PubMed: 23380931] Hess LH, Jansen M, Maybeck V, Hauf MV, Seifert M, Stutzmann M, Sharp ID, Offenhausser A, Garrido JA. Adv Mater. 2011; 23:5045. [PubMed: 21953832] Zhang AQ, Lieber CM. Chem Rev. 2016; 116:215. [PubMed: 26691648]

16. Gao K, Huang X, Chiang CL, Wang X, Chang L, Boukany P, Marcucci G, Lee R, Lee LJ. Mol Ther. 2016; 24:956. [PubMed: 26782640]

17. Gao K, Li L, He L, Hinkle K, Wu Y, Ma J, Chang L, Zhao X, Perez DG, Eckardt S, McLaughlin J, Liu B, Farson DF, Lee LJ. Small. 2014; 10:1015. [PubMed: 24173879]

18. Chang LQ, Bertani P, Gallego-Perez D, Yang ZG, Chen F, Chiang CL, Malkoc V, Kuang TR, Gao KL, Lee LJ, Lu W. Nanoscale. 2016; 8:243. [PubMed: 26309218]

19. Zhang Y, Huang XR, Wei LH, Chung ACK, Yu CM, Lan HY. Mol Ther. 2014; 22:974. [PubMed: 24569834]

20. Slusarz A, Pulakat L. J Cardiovasc Med (Hagerstown). 2015; 16:480. [PubMed: 25689084]

21. Perciavalle RM, Stewart DP, Koss B, Lynch J, Milasta S, Bathina M, Temirov J, Cleland MM, Pelletier S, Schuetz JD, Youle RJ, Green DR, Opferman JT. Nat Cell Biol. 2012; 14:575. [PubMed: 22544066]

22. Lv B, Liu ZH, Wang SP, Liu FB, Yang XJ, Hou JT, Hou ZK, Chen B. Int J Clin Exp Patho. 2014; 7:8542.

23. Arnold N, Koppula PR, Gul R, Luck C, Pulakat L. Plos One. 2014; 9

24. Kawai M, Kawashima S, Sakoda T, Toh R, Kikuchi A, Yamauchi-Takihara K, Kunisada K, Yokoyama M. Hypertension. 2003; 41:956. [PubMed: 12642511] Tatsuguchi M, Seok HY, Callis TE, Thomson JM, Chen JF, Newman M, Rojas M, Hammond SM, Wang DZ. J Mol Cell Cardiol. 2007; 42:1137. [PubMed: 17498736]

25. Skelley AM, Kirak O, Suh H, Jaenisch R, Voldman J. Nat Methods. 2009; 6:147. [PubMed: 19122668] Kobel S, Valero A, Latt J, Renaud P, Lutolf M. Lab Chip. 2010; 10:857. [PubMed: 20300672]

26. Henslee BE, Morss A, Hu X, Lafyatis GP, Lee LJ. Anal Chem. 2011; 83:3998. [PubMed: 21473595]

27. Chang LQ, Gallego-Perez D, Zhao X, Bertani P, Yang ZG, Chiang CL, Malkoc V, Shi JF, Sen CK, Odonnell L, Yu JH, Lu W, Lee LJ. Lab Chip. 2015; 15:3147. [PubMed: 26105628] Salimi E, 
Nikolic-Jaric M, Cabel T, Braasch K, Jung V, Butler M, Thomson DJ, Bridges GE. Ieee Imtc P. 2013:403.

28. Chiou PY, Ohta AT, Wu MC. Nature. 2005; 436:370. [PubMed: 16034413]

29. Chang LQ, Howdyshell M, Liao WC, Chiang CL, Gallego-Perez D, Yang ZG, Lu W, Byrd JC, Muthusamy N, Lee LJ, Sooryakumar R. Small. 2015; 11:1818. [PubMed: 25469659]

30. Djurovic S, Iversen N, Jeansson S, Hoover F, Christensen G. Mol Biotechnol. 2004; 28:21. [PubMed: 15456960]

31. Neu WK, Neu JC. Ser Biomed Eng. 2010:85.

32. Huang XM, Schwind S, Yu B, Santhanam R, Wang HY, Hoellerbauer P, Mims A, Klisovic R, Walker AR, Chan KK, Blum W, Perrotti D, Byrd JC, Bloomfield CD, Caligiuri MA, Lee RJ, Garzon R, Muthusamy N, Lee LJ, Marcucci G. Clin Cancer Res. 2013; 19:2355. [PubMed: 23493348]

33. Bertani P, Lu W, Chang LQ, Gallego-Perez D, Lee LJ, Chiang C, Muthusamy N. J Vac Sci Technol B. $2015 ; 33$

34. Zudans I, Agarwal A, Orwar O, Weber SG. Biophys J. 2007; 92:3696. [PubMed: 17351001] 
a

(i) Micro-cap array pattern

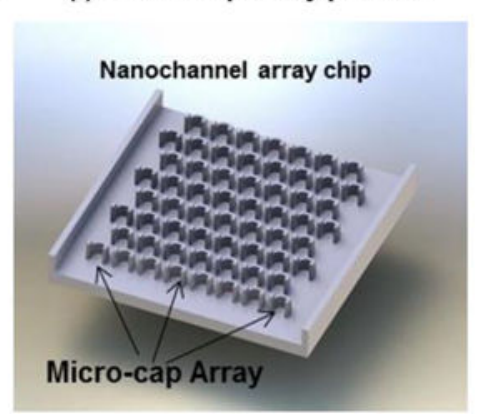

b
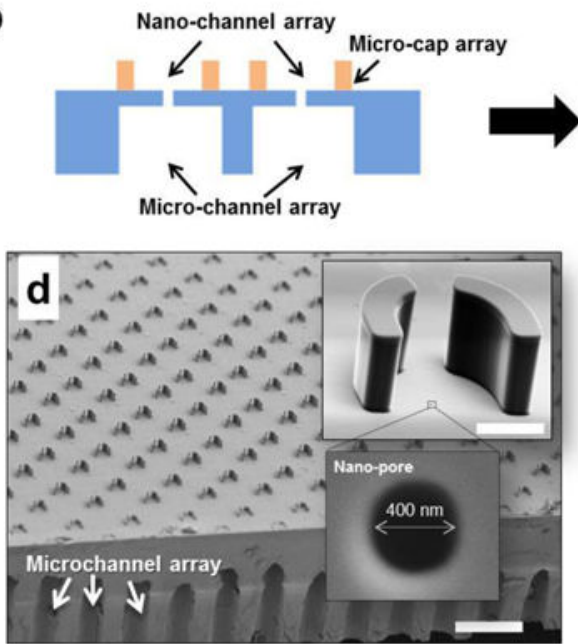

(ii) Chip dipping- dewetting

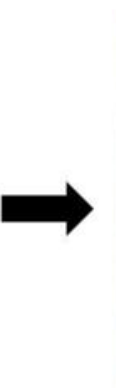

(iii) Large-scale cell trapping
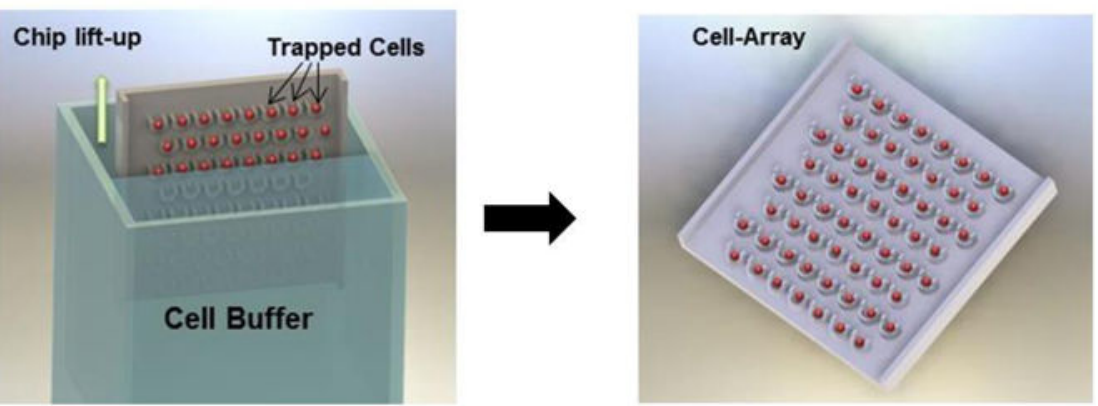

C

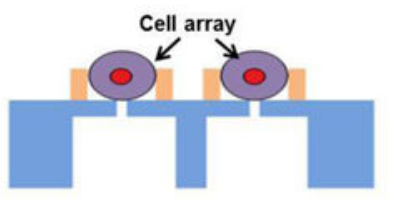

e

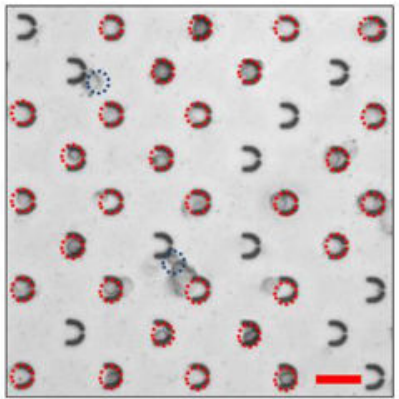

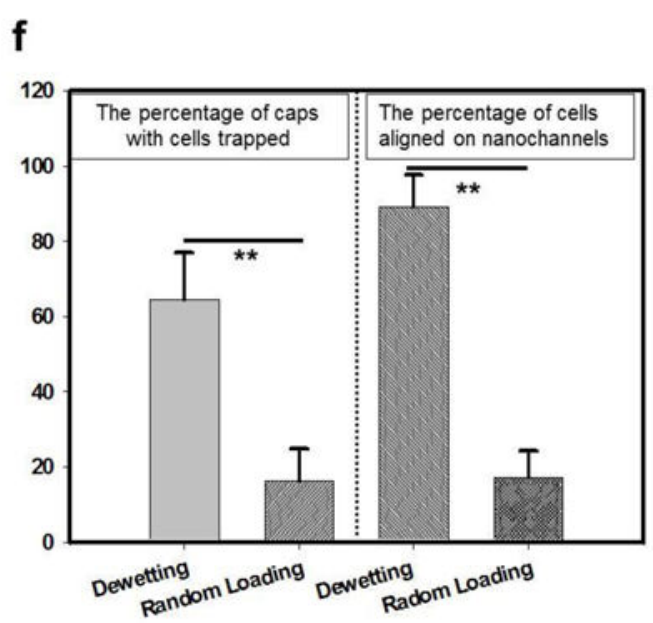

Figure 1. 'Dewetting' method for efficient and rapid cell trapping on the nanochannel array chip (a) The schematics showing 'dewetting' procedure for cell trapping, including (i) patterning 'U-shape' micro-cap array on chip; (ii) dipping the chip into cell buffer solutions, and vertically lift-up; (iii) the cells are trapped on the micro-caps driven by gravities and hydrodynamics. (b) and (c) show the cross-section of the chip before and after cells are trapped in micro-caps, respectively. (d) SEM micrograph of one type of micro-cap array ('interlaced' arrangement) patterned on the chip. The inset show the detail of one nanochannel region (single nanopore, $400 \mathrm{~nm}$ in diameter) which is surrounded by a single micro-cap. (e) Cellular array are trapped on chip using dewetting, showing single cell and single micro-cap pair. (f) The performance of dewetting method with the trap-design of (d) as compared to control group (cell random loading). Two parameters are considered, including the capture efficiency (left, the percentage of micro-caps with cells trapped) and the trapping specificity (right, the percentage of cells aligned on nanochannels). Scale bar: (d) $100 \mu \mathrm{m}$, (inset) $5 \mu \mathrm{m}$, (e) $50 \mu \mathrm{m}$. **: p-value $<0.01$. 

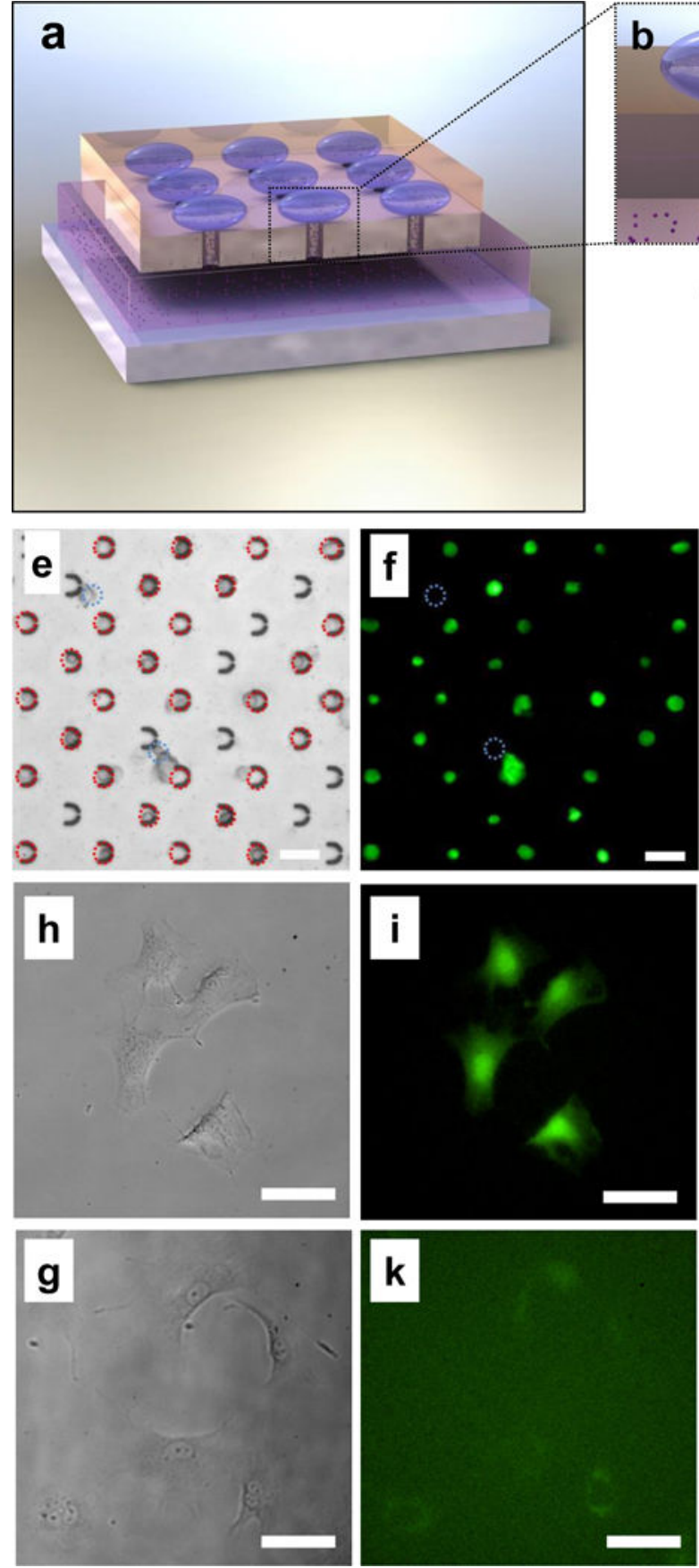
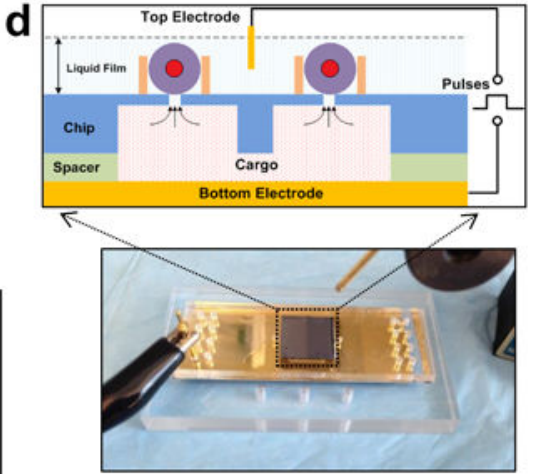

g

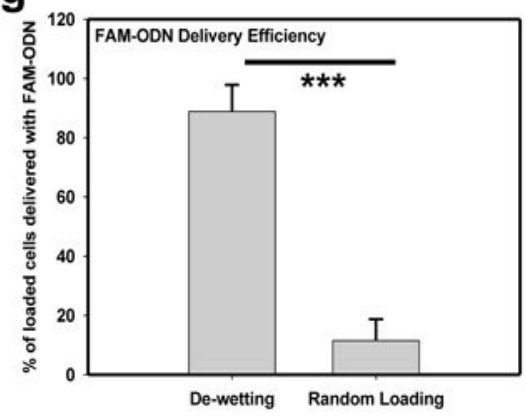

I

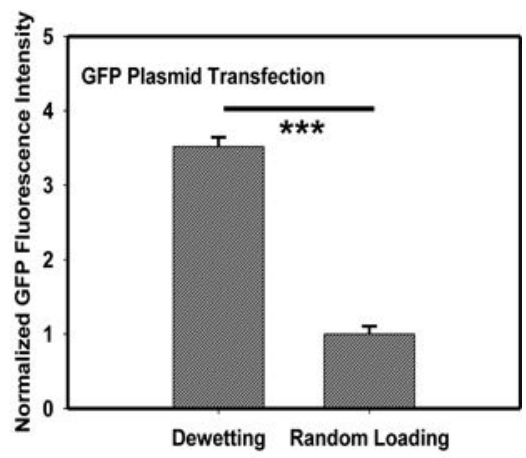

Figure 2. Massively parallel cargo delivery into trapped cells by nanochannel-based electroporation

(a) The schematic of the nano-electroporation system for Z-directional cargo delivery into cells trapped on the nanochannel array by 'dewetting' technique. (b) A single cell aligned on a nanochannel is electroporated and biomolecules are delivered into the cell through the nanochannel. (c) Confocal microscopy image shows a trapped cell (stain with Calcein AM, green fluorescence) is tightly contact a nanochannel (transmission white light) which enables efficient electroporation. (d) The cross-section schematic illustrates the nanochannel-based electroporation platform, consists of a bottom electrode, PDMS spacer, 
the chip with trapped cells and a top electrode. Electric pulses are applied between the electrodes to electroporate the cells in the proximity of the nanochannels while electrophoretically driving the biomolecules from the bottom chamber into cells. (e) Fluorescence labelled-oligonucleotides (FAM-ODN) delivered into the cells trapped on chip (labelled with red circle) result in (f) obvious fluorescence. Cells 'non-trapped' (indicated with blur circle) by micro-caps are not delivered with ODN. (g) Dewetting significantly improves the delivery efficiency as compared to random cell loading. (h) and (i) Mouse embryonic fibroblasts (MEFs) transfected with nanochannel-based electroporation expressed GFP fluorescence. (1) The nano-electroporation assisted with dewetting method lead to significant enhancement for GFP transfection compared to control ( $\mathrm{g} \& \mathrm{k}$, random loading).

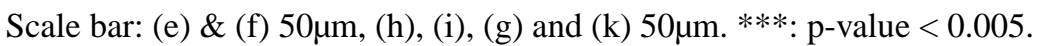




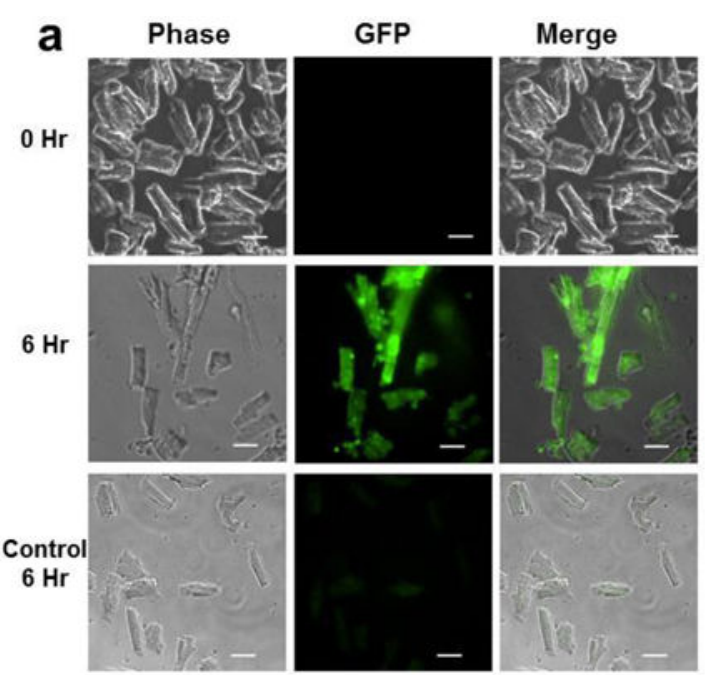

b

C

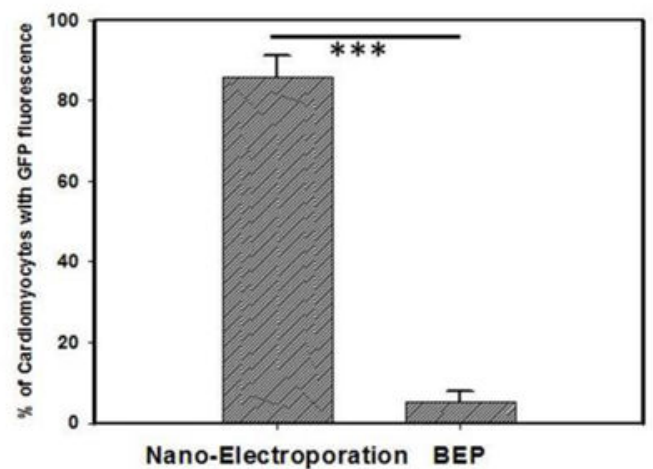

e

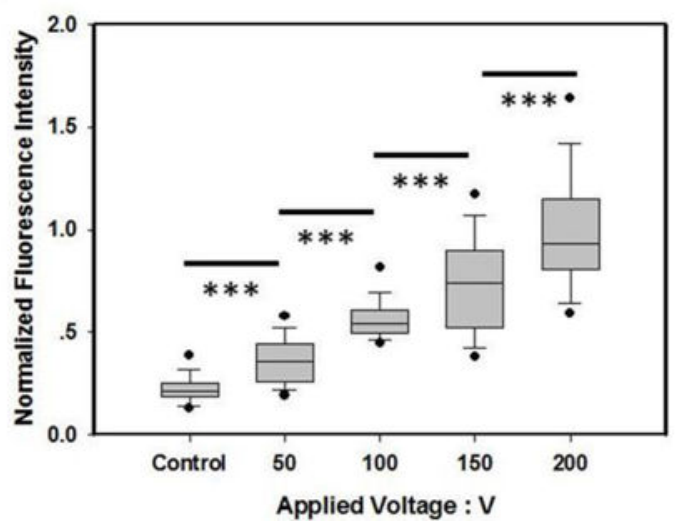

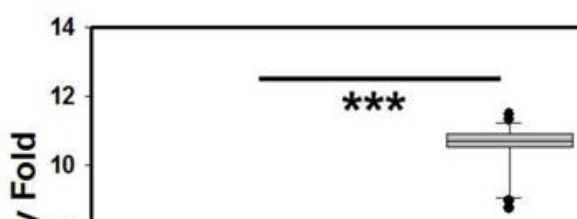

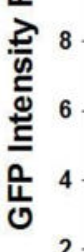

2

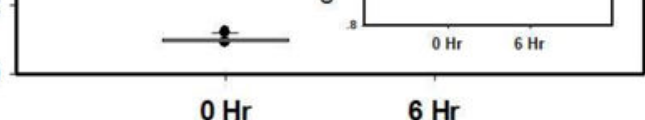

$\mathrm{OHr}$

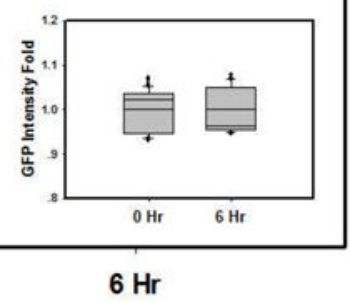

d

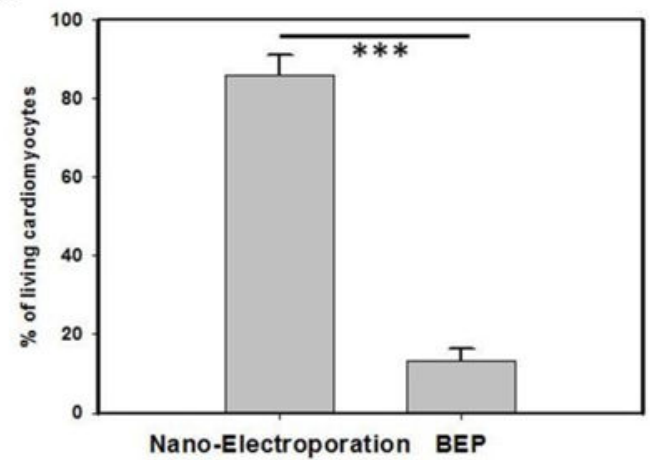

f

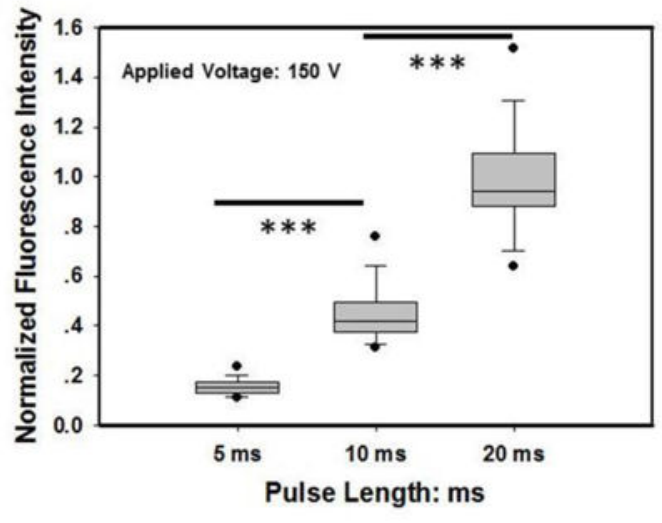

Figure 3. Safe and precise gene transfection of adult mouse cardiomyocytes on the nanochannelbased electroporation

(a) Fluorescence images and (b) statistics of GFP fluorescence expression $6 \mathrm{hr}$ after delivery of GFP plasmids (condition: $200 \mathrm{~V}, 10 \mathrm{~ms}$ pulse length) compared to control. Scale bar: 50 $\mu \mathrm{m}$. (c) The transfection efficiency and (d) the cell viability were compared between the nano-electroporation and BEP group. Precise dosage control can be achieved in mass cells $(10,000$ cells) by either (e) applied voltage and (f) pulse length. $* * *$ : p-value $<0.005$. 

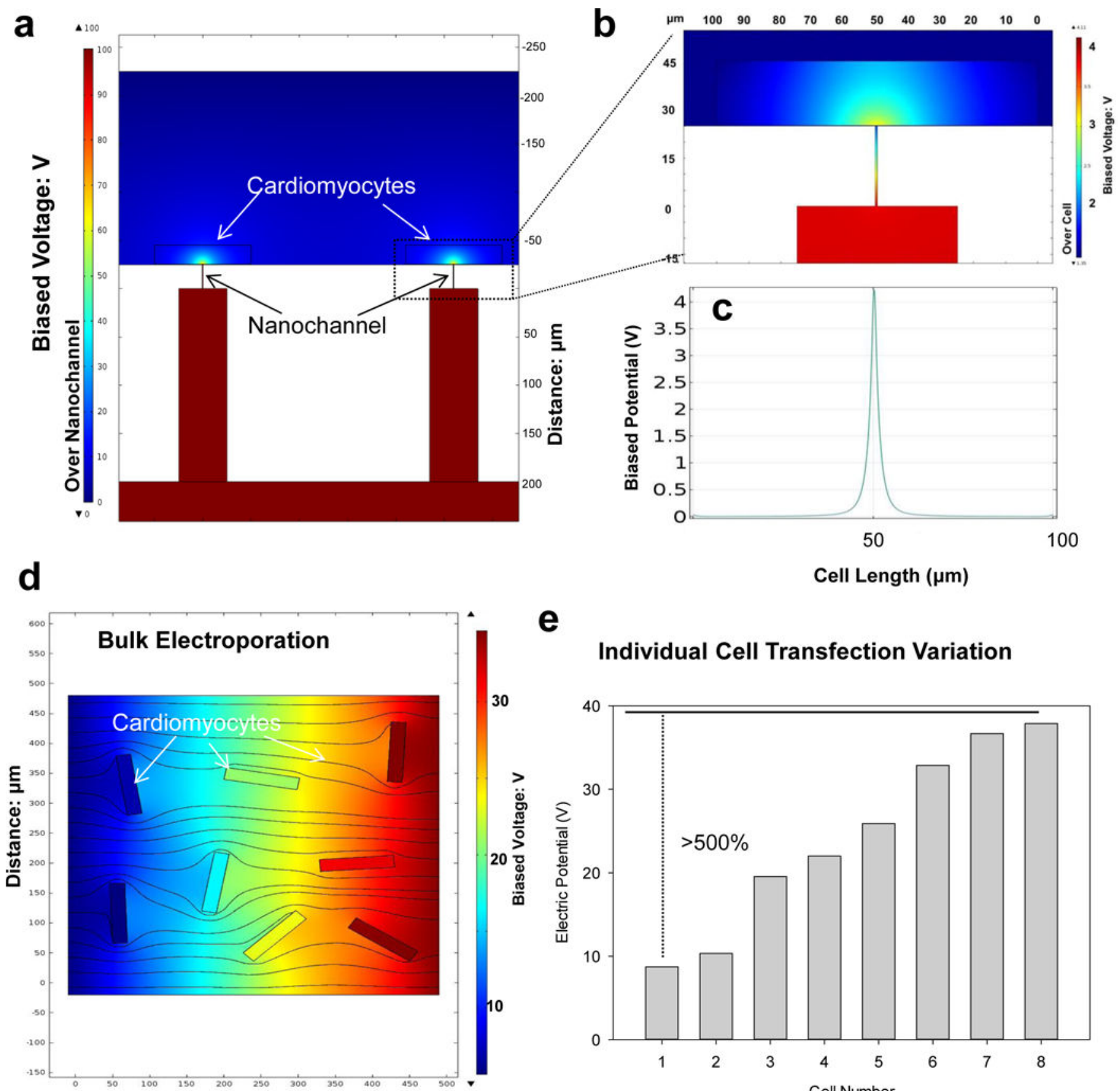

e

Individual Cell Transfection Variation

Figure 4. Physical simulations of electric fields in nanochannel- and bulk- electroporation for cardiomyocytes transfection

(a) The distribution of biased voltage in nanochannel where two single cardiomyocytes are localized. (b) Due to high resistivity of nanochannel, most of the applied voltage occur across the nanochannel $(\sim 96 \mathrm{~V})$, while a low potential drop $(\sim 4 \mathrm{~V})$ over the cell membrane, which is benign for single cell electroporation. (c) Biased potential along the cell membrane reveals only a tiny region of the cell membrane close to nanochannel has high potential to be porated. (d) In contrast, cells are electroported stochastically in the bulk solutions in BEP, which causes (e) a huge variation of biased voltages applied on individual cells. 
a
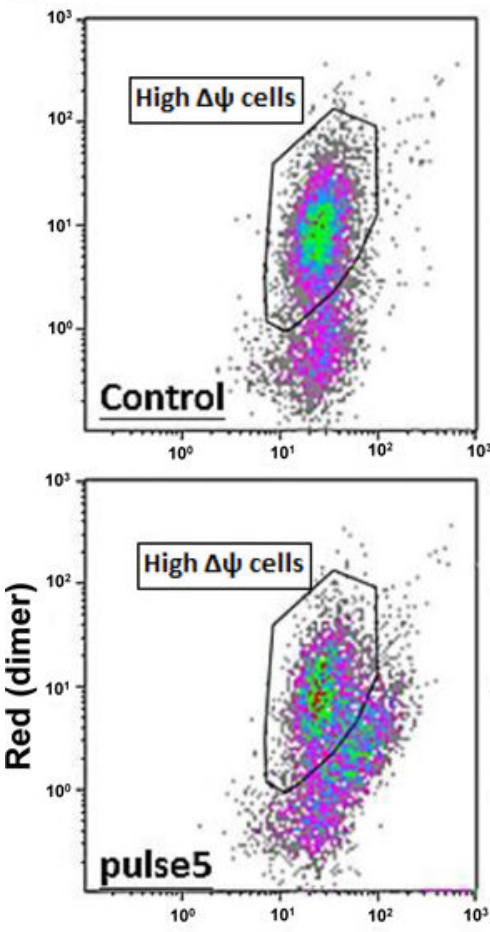
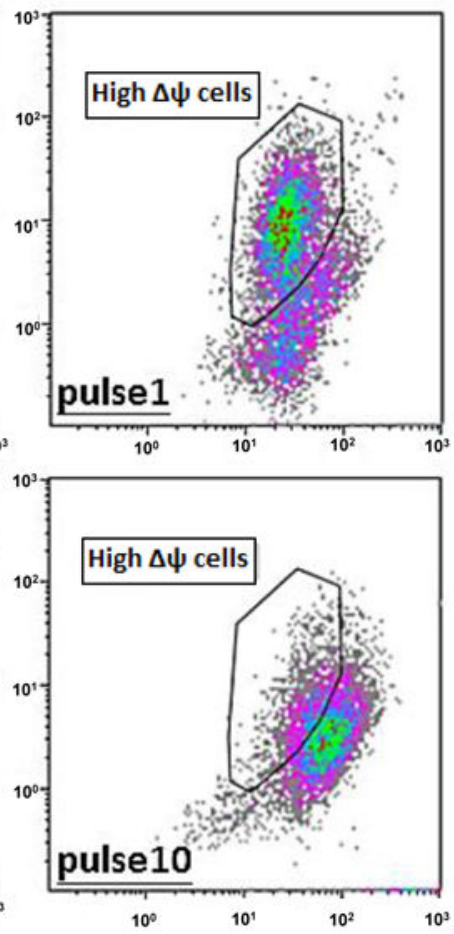

C
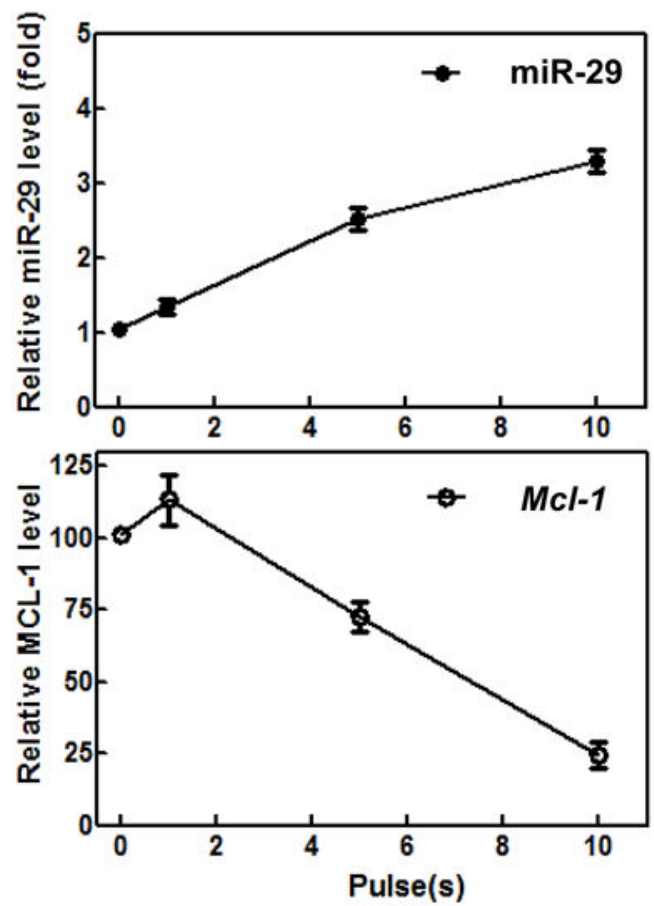

b
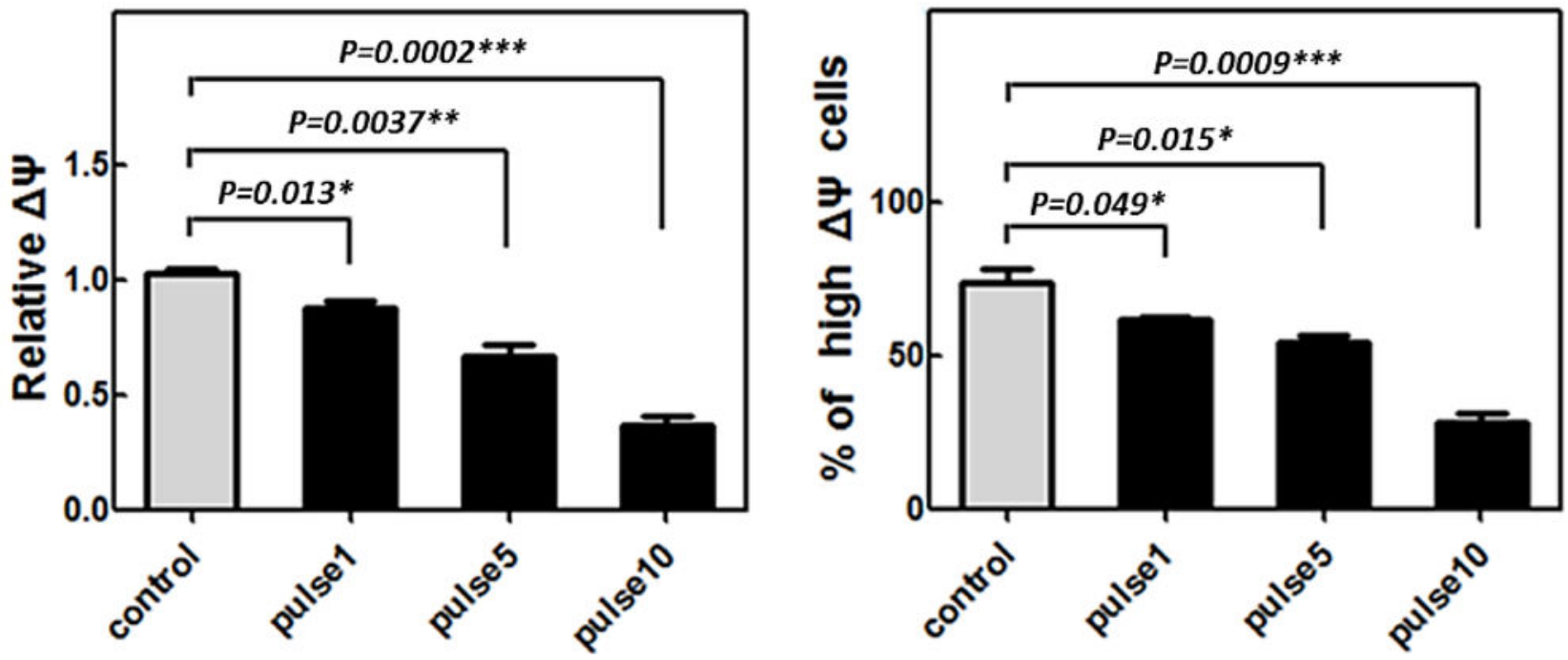

Figure 5. Controllable study of miR-29 dose-dependent treatment in primary mouse cardiomyocytes

(a) The primary cardiomyocytes from adult mice were isolated and injected with miR-29 with different pulses $(1,5,10$. Pulse duration: $15 \mathrm{~ms})$. The transfected cells were stained with JC-1 and analyzed by flow cytometry. The ratio of red (dimer)/green (monomer) reflected to the mitochondrial potential $(\Delta \Psi)$. (b) The dose-dependent reduction of $\Delta \Psi$ by miR-29 was observed. The percentage of high $\Delta \Psi$ cells was decreased by miR-29. (c) The 
relative amount of intracellular miR-29b and Mcl-1 mRNA was measured by real-time PCR, suggesting linear relationship between pulse umber and dose of miR-29. 